\title{
Power Cable Cost Benefit Analysis: A Critical Review
}

\author{
Yang Yang \\ Electronic and Computer \\ Engineering \\ Brunel University London \\ London, UK \\ yang.yang@brunel.ac.uk
}

\author{
Mohamed Darwish \\ Electronic and Computer \\ Engineering \\ Brunel University London \\ London, UK \\ mohamed.darwish@brunel.ac. \\ uk \\ Gareth O'Brien \\ Enertechnos \\ London, UK \\ gareth.obrien@enertechnos.c \\ om
}

\begin{abstract}
Many developed countries are facing a fundamental shift in the way electricity is generated and in the way electricity is consumed. The current T\&D network which was built for remote generation flowing to users at the ends and now has to cope with distributed generation across the network. The research on different parts of T\&D system faces the challenge and opportunity to optimise, to enhance the existing electric network in isolated mid-scale integrated generation and consumption networks. As the efficiency improvement of power cables will have a remarkable effect on the reduction of electricity dissipation and carbon emissions, researchers never cease exploring novel cable systems, e.g. Gas Insulated Line (GIL), High Temperature Superconductor (HTS), High Voltage Direct Current (HVDC) cables, Capacitive Transfer System (CTS) cables etc., but there is no systematic analysis of the practicality of comparing various cable options in mid-scale network. The purpose of this paper is to compare the cost and benefit among various types of power cables to provide a framework of reference for both researchers in this field and for generators, suppliers and consumers of electrical power who may be interested in the application of power cables using life cycle costing.
\end{abstract}

Keywords-Power Cable; Cost Benefit Analysis

\section{INTRODUCTION}

Power cable was first invented in 1880s. It has experienced great changes from the first designs in last 130 years. Now, the with the rise in distributed generation using offshore and onshore wind energy, solar energy and other intermittent renewables there are new challenges in power transmission and distribution in its current shape and configuration. Many developed countries, including the UK, are facing a fundamental shift due to the profound changes in electricity generation (e.g., different renewable energy technologies) and electric demand (e.g., the trend of electric transportation),

\author{
Mansour Moghadam \\ Enertechnos \\ London, UK \\ mansour@enertechnos.com
}

\author{
Charles Lucas-Clements \\ Enertechnos \\ London, UK \\ charles.lucas- \\ clements@enertechnos.com
}

\author{
Dominic Quennell \\ Enertechnos \\ London, UK \\ dominic.quennell@enertechno \\ s.com
}

which causes localised clustering of excess supply and usage over differing times of the day or night. The research for the resulting different scales of T\&D solutions faces the challenge and opportunity to optimise, to enhance the existing electric network by the improvement of mid-scale networks or interlinks.

In the existing T\&D networks, especially in urban areas, there are reduced choices for transmission technologies by distributed network operators, because the application of overhead lines (OHLs), especially bare lines, are not viable in a local residential area in spite of the low costs of investment of OHLs. Under the provisions of the Planning Act 2008, all new OHLs must have approval from Infrastructure Planning Commission (IPC) or, from April 2012, when the Localism Bill takes effect, from the Secretary of State [1]. Consequently, researchers are motivated to explore and develop novel cables, e.g. HVAC extruded cables [2], GILs [3], HVDC extruded cables [4], HTS cables [5], and CTS cables etc., but there is no systematic analysis to compare the cost and benefit with existing cables in mid-scale networks on an all-encompassing common basis.

Cost benefit analysis can be seen from different viewpoints. Usually involving the consideration of the service life of a T\&D power cable, investment cost, operation cost, and replacement cost, which is notionally called Life Cycle Cost Analysis (LCCA) [7], as shown in Fig. 1. Although social, planning and environmental costs may be potential additional generic costs, they are not discussed in this paper. 


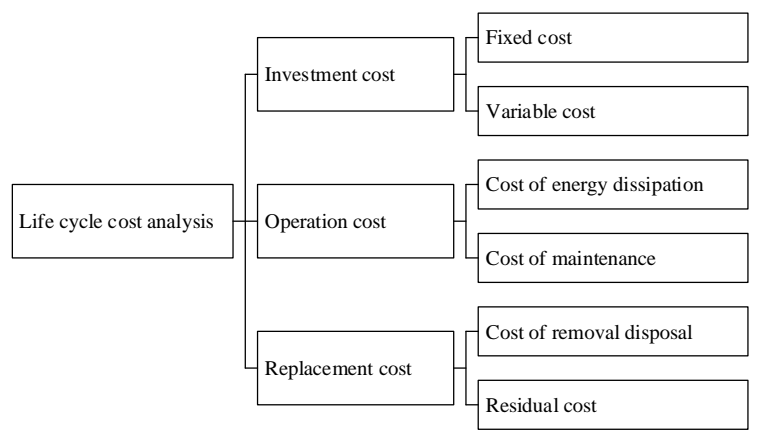

Fig. 1. Life cycle cost analysis framework in power cables

Moreover, in order to make full use of power cables in a T\&D system with high reliability, degradation and failure probability of different power cable options need to be taken into consideration to evaluate the effective service life [8], as early retirement and unexpected failures will result in economic losses. Currently, recorded historical failure data had been applied to establish databases for predicting performance and failure rate of power cables [9]. When the failure rate exceeds an acceptable level, the cable asset should be replaced proactively. Weibull Analysis [10], Crow-Army Material System Analysis Activity (AMSAA) [11], Markov model [12] and Nonhomogeneous Poisson Processes (NHPP) [13] models have been applied in failure prediction and trend evaluation, as they had different applicable scopes and advantages.

Last but not least, the importance of annual cost of energy dissipation of a cable system is often underestimated in comparison with fixed asset costs. As the improvements of new cable technology and the development of continuous monitoring technologies extend the potential life times, the converted annual cost of fixed assets (amortisation) is decreasing, while the annual cost of energy dissipation is increasing with the electricity price growth. The energy losses of different cable technologies should be well considered.

Consequently, the purpose of this paper is to review different power cable technologies, to summarise the LCCA framework of references, to review the failure forecast models and to compare the energy losses for different cable technologies. This can be used as a guideline for selecting cable technologies within a cost and benefit perspective.

\section{Power Cable Technology}

\section{A. HVAC extruded cable}

Currently, HVAC extruded (underground) cables are widely used in T\&D systems for high-capacity electricity transmission resulting in a lower effect on the environment in cities than OHLs. When transmitting the same power, HVAC cables need larger conductor cross section than that OHLs, because of the limitation of solid insulation thermal conductivity. Consequently, the reason why the cost of a HVAC cable is 4-10 times higher, than that of an $\mathrm{OHL}$, is because cables require more conductor and insulation material [1] and the cost of burial. Moreover, in some special cases, cable tunnels are required that leads to increased investment costs for the cable system. Fig. 2 demonstrate a 400 kV HVAC cable tunnel in London and a Cross-bonded Polyethylene (XLPE) insulated HVAC cable structure.

\section{B. GIL}

GIL is a feasible alternative to OHLs and conventional underground cables (UGCs), and are filled with insulating gas, e.g. N2 and SF6 mixture [14]. Due to better insulating performance than that of air, the radius of GIL insulation can be smaller than that of $\mathrm{OHL}$. However using the better thermal conductivity of gas rather than that of solid insulation material, e.g., Cross-linked Polyethylene (XLPE) and Ethylene Propylene Rubber (EPR), GIL can transfer larger load current without the insulation overheating. Moreover, GIL can work properly with less maintenance [15]. The induced current in the metal housing of a AC GIL can offset the inner magnetic field, but with potential risk to maintainers. So, because of this, GIL is normally used in DC electric transmission mode [16]. But GIL DC cables has to consider the significant additional fixed asset cost, e.g., investment in converters, on both ends of transmission lines [15]. Fig. 3 shows a GIL tunnel designed by Siemens and the typical GIL structure.

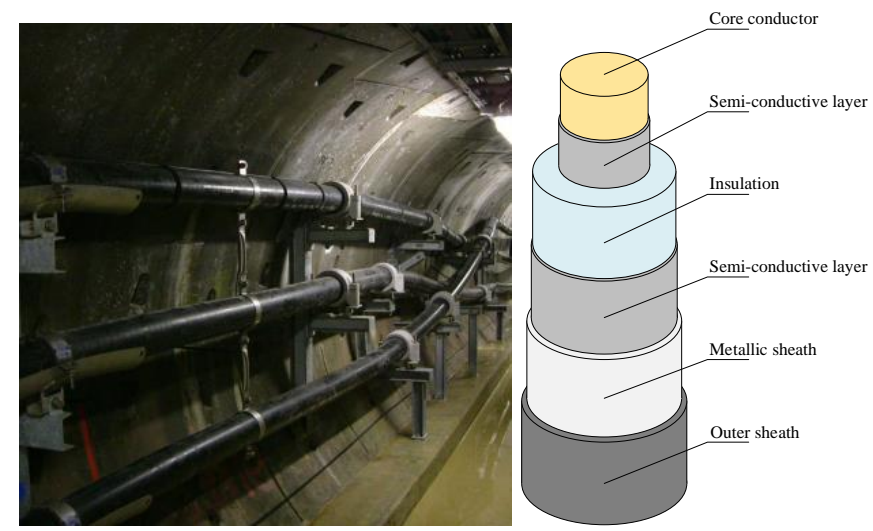

Fig. 2: HVAC cable tunnel and HVAC cable structure

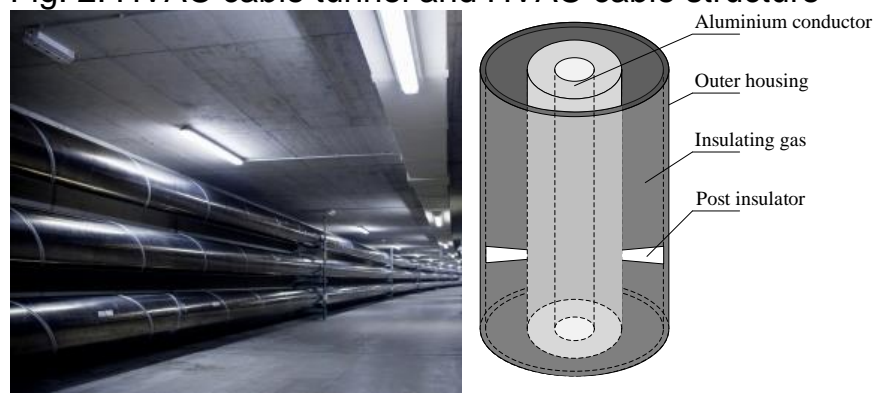

Fig. 3: GIL cable tunnel and GIL structure

\section{HVDC extruded cable}

HVDC extruded cables usually have a similar cable structure to that of HVAC extruded cables for longdistance point-to-point electric transmission, e.g., 
submarine power cables. Due to the maturity and acceptance of extruded solid insulation material, fluid insulated cables applied in submarine power transmission are being substituted gradually by XLPE insulated cables, as shown in Fig. 2. But HVDC extruded cables also face a same dilemma as that of GIL DC cables, since the significant cost of converters on both ends of transmission lines have to be included [15].

\section{HTS cable}

HTS and LTS (i.e., Low Temperature Superconductor) cables are two cable technology use superconductor technology to decrease the line losses and to increase the electric transmission capacity [15]. However, when the HTS technology is applied to AC electric transmission, it suffers fromhigh induced magnetic losses beyond the inner super-conductors. So when the load current is in the order of thousands of Amps it has huge magnetic emissions and causes significant induction in the adjacent conductors. So, HTS cables are usually only accepted in DC transmission line load. Because of this, the effect and the protection strategies under huge load currents on the network should be well considered. Fig. 4 shows a 66kV HTS cable in Japan and the typical HTS cable structure.
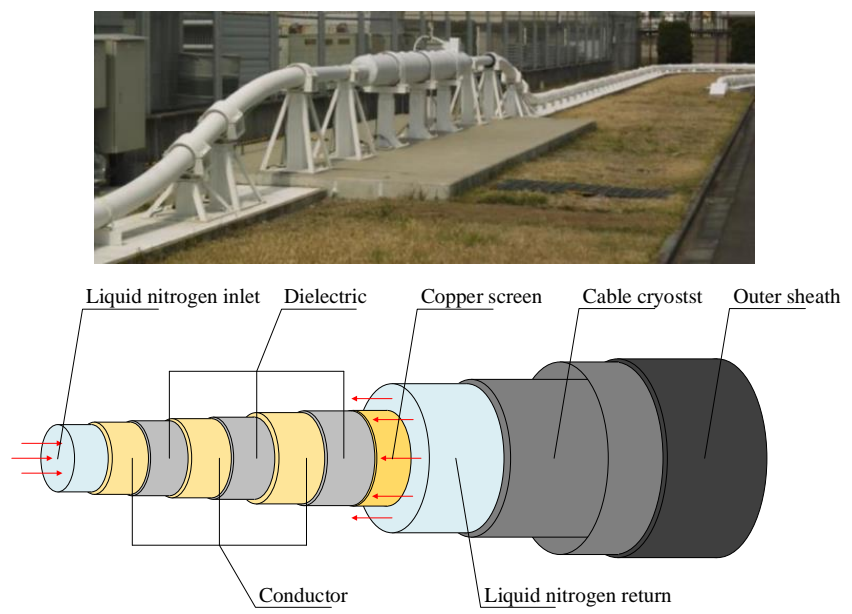

Fig. 4: HTS cable line and typical HTS cable structure

\section{E. CTS cable}

CTS cable is configured as a combination of a capacitor and power cable and offsets the reactance and reduces the skin effect of the core conductor. CTS provides the potential to decrease voltage drop and to increase the system power factor without any extra investment in reactive power compensation devices. In contrast, a conventional AC extruded cable has an obvious skin effect especially when using larger cross section areas (e.g., for a $630 \mathrm{~mm}^{2}$ cross section area the conductor radius is $14.2 \mathrm{~mm}$ but the skin effect depth is $9.2 \mathrm{~mm}$ at a frequency is $50 \mathrm{~Hz}$ ). This causes increased resistance in core conductors because the current has less area to move through. CTS gives a solution to reduce the skin effect by adding dielectric between strands to block the path of eddy currents. Fig. 5 shows the concept of a single-phase CTS [6].

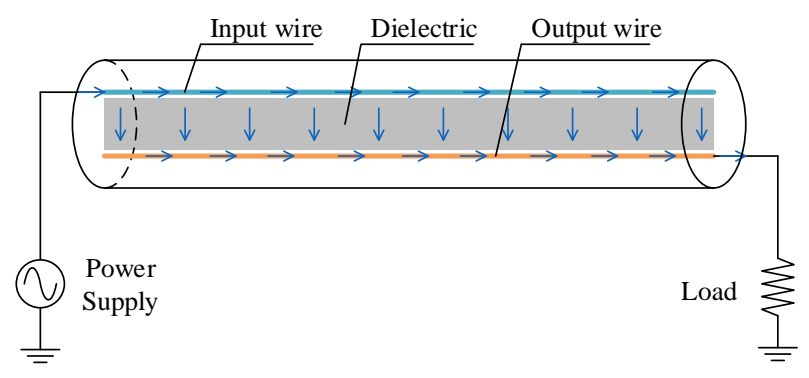

Fig. 5: Simplified Single-phase CTS cable concept

\section{LIFE CYCLE COST ANALYSIS}

Due to various factors and various of selections involved in any electric transmission project, cost estimation is an essential element and needs to be rigorously applied. LCCA gives a systematic view to evaluate the cost and benefit of a cable technologies proposed in Section II. LCCA will be reviewed from three aspects, including investment cost, operation cost and replacement cost.

\section{A. Investment Cost}

Investment cost of a power cable system is the cost elements made up from the fixed asset, land, route design, transportation and installation, which can be divided into fixed cost and variable cost based upon distance [17], as shown in Fig. 6. The investment cost is symbolized as $C_{i}$, which can be expressed by (1).

${ }^{*}$ Converter stations, cooling systems and tunnels are not always required in a cable system, but should be included for those scenario's that need them.

$$
C_{i}=C_{i f}+C_{i v}
$$

Where, $C_{\text {if }}$ is the fixed cost independent upon distance; $C_{i v}$ is the variable cost based on distance.

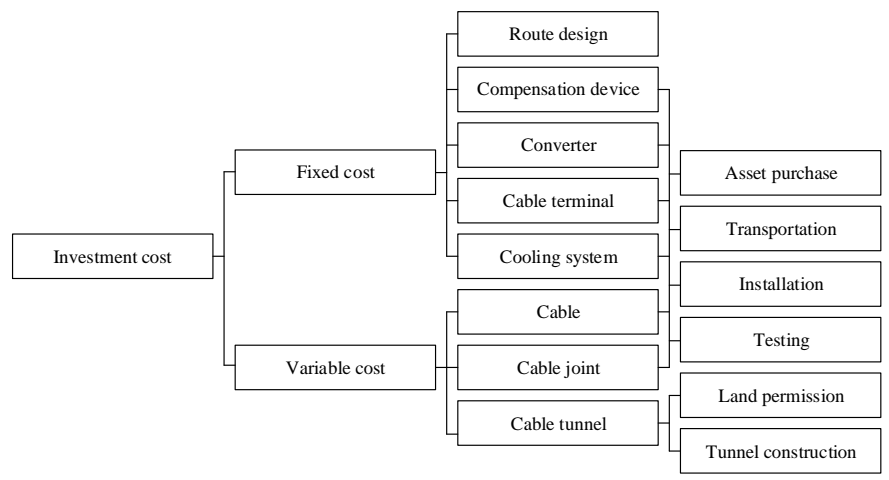

Fig. 6: Components of investment cost

The investments in converter stations (e.g., a requirement for HVDC), cooling systems (e.g., required for HTS), compensation device (e.g. the application in HVDC and HVAC) or cable tunnels can be the largest 
part of the investment costs. With the increase of transmission length, the cost of cable and its accessories will increase, the fixed costs will reduce.

\section{B. Operation cost}

After the construction and installation of a cable system, operation and maintenance costs are the main cost of the network, as shown in Fig. 7. Operation cost, $C_{0}$, can be expressed by (2) [18].

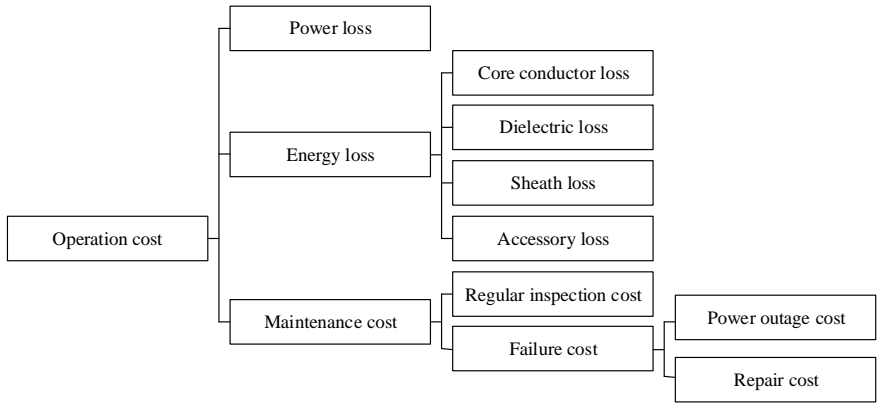

Fig. 7: Components of operation cost

$$
C_{o}=C_{o e}+C_{o m}+C_{o p}
$$

Where, $C_{o e}$ is the energy dissipation cost;

$C_{o p}$ is the costs of installing the extra generation necessary to supply the energy losses;

$C_{o m}$ is the inspection and maintenance cost.

The costs of maximum power losses, $C_{o p}$, are the costs of installing the extra generation necessary to supply the energy losses which will ultimately heat up the atmosphere. These generators must be capable of supplying the peak losses. The marginal cost should be based on Natural gas as the default top up fuel. This may involve an assumed average power factor.

During the service life of a cable system, the main operation cost is the energy loss, which is related to the physical characteristics and operation state of the transmission line. Energy losses of a cable system are made up from losses in conductors, dielectric, sheath and accessories. In an AC system, the energy losses from any compensation devices should be considered. In a DC system, the energy losses from converters should be considered. Moreover, in a HTS system, cooling system losses should also be considered.

In order to ensure the safety and reliability of power cables, power cables are required to be regularly inspected and maintained [19], which can be expressed by (3).

$$
C_{o m}=C_{o m i t m i L n}+C_{o m f}
$$

Where, $C_{\text {omi }}$ is the inspection cost of each cycle per km;

$C_{\text {omf }}$ is the failure cost;

$L$ is the length of the line;

$n$ is the service life.

$t_{m i}$ is the inspection cycle per year.

\section{Replacement cost}

Due to degradation and failures, at the end of service life of power cables, substitution will be carried out with replacement cost $C_{r}$. Some equipment or recyclable materials in a cable system have residual value. The replacement cost of a power cable system includes the economic loss of early retirement and removal disposal cost, and it should have the residual cost subtracted, as shown in (4) and Fig. 8 [20].

$$
C_{d}=C_{d d}+C_{d r}-C_{d v}
$$

Where, $C_{d d}$ is the removal cost;

$C_{d r}$ is the disposal cost

$C_{d v}$ is the residual value.

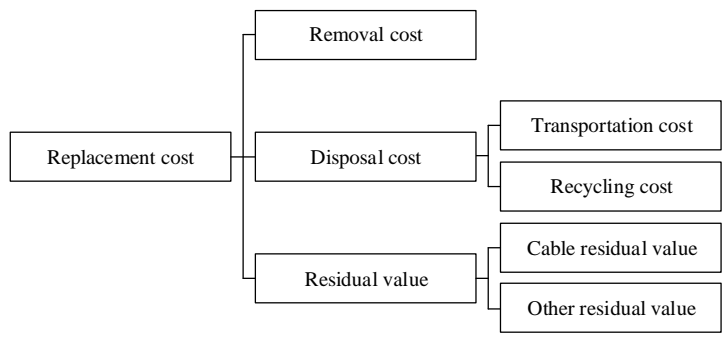

Fig. 8: Components of replacement cost

\section{FAILURE PROBABILITY}

During service life of power cables and their accessories, these power assets are under various influential factors, including environmental, mechanical, chemical, electrical and thermal pressures, which cause the accelerated degradation and unexpected failures . Failure cost is considered as an important factor in maintenance cost, which can be expressed by (5).

$$
C_{o m f}=\lambda\left(C_{o m f r}+C_{o m f o}\right)
$$

Where, $C_{\text {omf }}$ is the failure cost of a power cable system; $\lambda$ is the fault rate;

Comfr is the repair cost of each fault;

$C_{\text {omfo }}$ is the power outage loss of each fault.

Failure rate, $\lambda$, describes the possibility or frequency of a power cable failing in its service life cycle, which obeys the bathtub curve, as shown in Fig. 9 [10]. In the first stage, quality problems caused by manufacturing lead a high failure rate at the early stages; in the third stage of the life cycle, degradation causes the failure rate to increase gradually. Usually, cables retire before the third stage.

Several models have been proposed to predict the failure rate of power cables. The Weibull model proposed by Ainscough P. E. [21] studied the relationship between the number of failures and their time-to-failure to forecast the number of future failures. However, the Weibull model ignored the fact that the remaining life of the cable mainly relies on operational stresses in service. Therefore, the failure rate varies with operational 
conditions such as load levels, installation methods and locations.

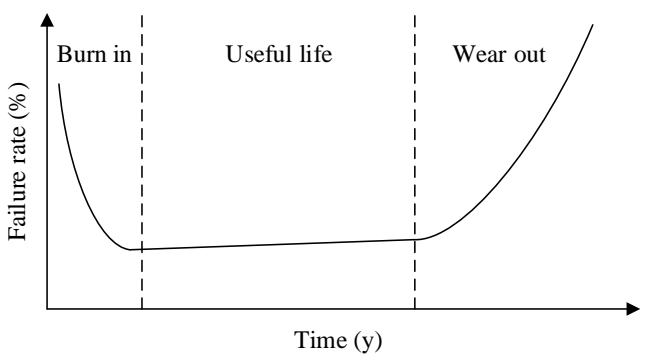

Fig. 9. Failure rate of power cable - bathtub curve

The Crow-AMSAA (C-A) model proposed by Barringer [22] was compared with the Weibull distribution. It indicated that the C-A model worked well with mixed failures, while the Weibull model was a powerful tool in single failure prediction. Moreover, these two models largely depend on life-time failure data. But some cable technologies, e.g., GIL, HTS, HVDC, CTS cables, lack statistics at all three stages.

Poisson distribution and Binomial distribution were adopted by CIGRE Working Group A3.06 [23] to calculate the probability of failures among high voltage equipment. However, these methods have an assumption that power cable failures are subject to certain statistical distributions. When a detected failure pattern does not fit any distributions, due to the lack of data homogeneity, the analysis results would fail to predict the future failure rate. In addition, none of the above methods consider influential factors that are most relevant to the failures of power cables.

The Cox proportional hazard model (Cox PHM) proposed by Cox was widely applied in medical domains to study the impact of influencing factors on the survival time of patients [24]. Compared with mentioned statistical models, the greatest advantage of the Cox PHM is the consideration of more than one covariates simultaneously. This is exactly the feature required in analyzing those failure data related to early failures. Moreover, the Cox PHM is a semi-parameter model which does not need to know the distribution of data with more adaptive and robust performance. But the covariates used in the Cox PHM should contain the entire cable sample. Otherwise, analysis can lead to misleading results.

A piecewise power-law non-homogeneous Poisson process (NHPP) model was proposed by Swati S., which assumed that cable sections are repairable [25]. NHPP model predicted the trend of total annual cable failures due to both random causes and degradation shown in Fig. 10. Probability of failure due to ageing increases rapidly after 6570 days (18 years) when the accumulated electro-thermal degradation starts approaching the threshold degradation level. Degradation in a cable life is the result of the mutual effects of thermal and electrical deterioration. The first application in estimation of cable life proposed by Mazzanti was based on the cumulative damage Miner's rule [26]. Electro-thermal degradation accumulation in a cable is of stochastic nature that was considered in the NHPP model based on on-line monitored data. The randomness in the thermal resistance of cable insulation and varying load current are the two main reasons of the stochastic nature of accumulated degradation. Piecewise power-law NHPP and stochastic electro-thermal degradation, are combined to estimate annual failures.

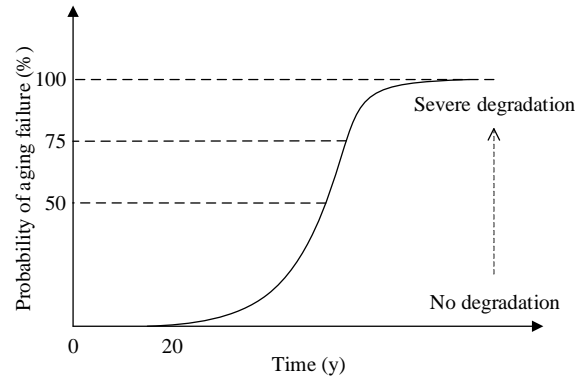

Fig. 10: Degradation rate of power cable insulation

\section{ENERGY LOSSES}

Investment cost is a one-time purchase that is considered as a main cost of a project, while energy loss in a cable system is a long-term cost based on the estimation of failure probability mentioned in Section IV. Energy loss also occupies a considerable proportion of the life cycle cost of a cable system. For a $400 \mathrm{kV} 75 \mathrm{~km}$ $3 \mathrm{GW}$ AC cable system, all fixed asset costs can reach $£ 300$ million, while the annual energy losses can reach $£ 130$ million [1]. Meanwhile, the average service life of a cable line can be 30 years, that is to say energy losses in a life cycle of a cable system can greatly exceed the fixed cost investment. Consequently, GIL, HVDC, HTS and CTS cable technology are aiming to decrease the energy loss during the service life at an increase fixed cost upfront.

\section{A. HVAC cable energy losses}

HVAC extruded cable energy losses are mainly from four parts, including conductor losses, dielectric losses, sheath losses and the losses from compensation device. Transmission connection losses (e.g., losses in joints and terminals) are relatively less than the losses from conductor, dielectric and metallic sheath.

\section{B. GIL cable energy losses}

GIL cables are gas insulated lines coated by metal housings. When an alternating current is applied as the load current in the core conductor of the GIL, there will be a sheath current similar to the value of the applied load current but in opposite direction in the metal housing. Although, the induced sheath current can be used to offset the magnetic field and decrease the magnetic emission, higher sheath losses and safety issues should be considered to construct GIL cable systems [27]. 
GIL cables are preferentially suited to DC electric power transmission, as the losses in the conductor is much lower than HVAC extruded cables. Meanwhile dielectric loss and sheath loss are ignorable due to the application of insulating gas and DC load current. However, DC system energy losses are mainly derived from converters and accessories. E.g., in a HVDC VSC cable system, the energy losses from converter can be twice of the conductor losses [33], which indicates the importance to consider the whole losses instead of line losses only when comparing different cable technologies.

\section{HVDC cable energy losses}

HVDC extruded power cables are usually similar geometry to HVAC extruded cables. This kind of cable technology faces the same disadvantages as GIL DC electric transfer in the higher losses in converter stations. This high fixed cost element thus benefit from longdistance cable applications [28].

\section{HTS cable energy losses}

Owing to the superconducting performance, HTS cable is feasible to transfer high AC or DC electric capacity. When transferring AC load current in three phases, the special design of three-phase conductor as shown in Fig. 4 can reduce the huge induced magnetic field.

But Francesco G. points out that hysteresis losses, eddy-current losses, coupling losses and ferromagnetic loss all contribute to the energy losses in adjacent metal parts [29]. Moreover, dielectric losses and cooling system losses are the main energy losses in a HTS cable system. Moreover, due to relatively high load current, current protection device and system fault protection should be considered [30].

\section{E. CTS cable energy losses}

CTS is designed to improve AC network systematic performance and decrease line reactance, reduce voltage drop and the substantially eliminate of skin effect in core conductors [6]. Consequently, it is feasible to reduce conductor losses in comparison with conventional AC cables. Moreover, the energy losses in transmission connections are still to be studied. E.g., the AC resistance of a conventional extruded power cable with a $630 \mathrm{~mm}^{2}$ cross section is $0.04 \Omega / \mathrm{km}$, while its reactance is $0.097 \Omega / \mathrm{km}$ at $50 \mathrm{~Hz}$ from Nexans datasheet [31]. As the reactance effect is greater than resistance, the reduction of reactance will improve the power quality and decrease the energy losses. Moreover, there is no need to provide any extra compensation devices to improve the power factor of the transmission line which also decrease the energy losses.

\section{CONCLUSIONS}

Although no one analysis method is appropriate in every circumstance, CBA can be seen as a systematic view for selecting one transmission technology over another in a specified scenario. However, the comparison needs to take account of all the benefits that the system experiences that are due to its application, or conversely add costs to those technologies that cannot perform in the same way. With the continuous development of new cable technologies, the fixed asset costs will be a decreasing trend in the future. Moreover, failure probability of a cable system indicating the useful life-time of a cable system is a key factor to determine the life cycle costs. The precise method to forecast the remaining life should combine the historical failure data and continuous monitored deterioration condition. In service, the main costs are from the energy losses in conductors, dielectric, metallic sheath and accessories. The accumulative cost of energy losses would be much higher than the one-time fixed investment. Cost benefit analysis gives an overlooking view of new power cable technology research and T\&D project investment, which needs more statistical analysis based on the data from different manufacturers, T\&D operators.

\section{REFERENCES}

[1] M. J. H. Sterling, "Electricity Transmission Costing Study," 2012.

[2] Harry Orton, "Power Cable Technology Review ", High Voltage Engineering, vol. 41, no. 4, pp. 1057-1067.

[3] H. Koch, Gas-insulated transmission line (GIL). Chichester, West Sussex, U.K.: John Wiley \& Sons Ltd, 2012, pp. 7-38.

[4] T. Hanley, R. Burford, R. Fleming and K. Barber, "A general review of polymeric insulation for use in HVDC cables", IEEE Electrical Insulation Magazine, vol. 19, no. 1, pp. 13-24, 2003.

[5] Shaotao Dai, Liye Xiao, Hongen Zhang, Yuping Teng, Xuemin Liang, Naihao Song, and et al., "Testing and Demonstration of a 10-kA HTS DC Power Cable", IEEE Transactions on Applied Superconductivity, vol. 24, no. 2, pp. 99-102, 2014.

[6] Paul L Mantock, MS Moghadam and Mohamed Darwish, "A Charge Transfer Cable (CTC)'an ultra-low loss cable'", in Universities Power Engineering Conference (UPEC), 2012 47th International, Uxbridge, UK, 2012, pp. 1-6.

[7] W. Boone, R. Bal and A. Kacker, "Copper or Aluminium cable conductors, broadly compared in a life cycle perspective", in Jicable 2015, Versailles, Paris, 2015, pp. E1.2:1-5.

[8] X. Si, W. Wang, C. Hu and D. Zhou, "Remaining useful life estimation - A review on the statistical data driven approaches", European Journal of Operational Research, vol. 213, no. 1, pp. 114, 2011.

[9] C. Zhou, H. Yi and X. Dong, "Review of recent research towards power cable life cycle management", High Voltage, vol. 2, no. 3, pp. 179-187, 2017.

[10] Z. Tang, W. Zhou, J. Zhao, D. Wang, L. Zhang, H. Liu, Y. Yang and C. Zhou, "Comparison of the Weibull and the Crow-AMSAA Model in Prediction of Early Cable Joint Failures", IEEE Transactions on Power Delivery, vol. 30, no. 6, pp. 2410-2418, 2015.

[11] Gill, JYancy. "Forecasting Underground Electric Cable Faults Using the Crow-AMSAA Model". Asset Management \& Maintenance Journal, Vol. 24, No. 1, Jan 2011: 40-41.

[12] L. Cheng, H. Feng, Y. Chang and C. Singh, "Reliability Analysis of HTS Cable Systems", IEEE Transactions on Power Delivery, vol. 30, no. 3, pp. 1251-1259, 2015.

[13] S. Sachan, C. Zhou, G. Bevan, and B. Alkali, "Failure prediction of power cables using failure history and operational conditions," in 2015 IEEE 11th International Conference on the Properties and Applications of Dielectric Materials (ICPADM), 2015, pp. 380383. 
[14] W. Sun, Y. Li, D. S. Zheng, R. Y. Guo, and X. H. Du, "Insulation Characteristics of SF6 / N2 Gas Mixtures and Applied Researches," in 2017 IEEE Electrical Power and Energy Conference (EPEC), 2013, pp. 879-882.

[15] Elnaddab, Khalifa, Evaluation of Gas Insulated Lines (GIL) for long distance HVAC power transfer. PhD Thesis, Cardiff University.

[16] H. Thomas, A. Marian, A. Chervyakov, S. Stückrad, D. Salmieri, and C. Rubbia, "Superconducting transmission lines - Sustainable electric energy transfer with higher public acceptance?," Renew. Sustain. Energy Rev., vol. 55, pp. 59-72, 2016.

[17] X. Xiang, M. M. C. Merlin, and T. C. Green, "Cost Analysis and Comparison of HVAC, LFAC and HVDC for Offshore Wind Power Connection," in 12th IET International Conference on AC and DC Power Transmission (ACDC 2016), 2016, p. 6 (1-6).

[18] D. Elliott et al., "A Comparison of AC and HVDC Options for the Connection of Offshore Wind Generation in Great Britain," IEEE Trans. Power Deliv., vol. 31, no. 2, pp. 798-809, Apr. 2016.

[19] H. M. Ryan, High-Voltage Engineering and Testing High-Voltage Engineering and Testing. 2013.

[20] Z. Zhu, S. Lu, B. Gao, T. Yi, and B. Chen, "Life Cycle Cost Analysis of Three Types of Power Lines in $10 \mathrm{kV}$ Distribution Network," Inventions, vol. 1, no. 4, p. 20, Oct. 2016.

[21] J. P. AinscoughP.Eand I.W.Forrest P. E, "Predicting mediumvoltage underground-distribution cable failures," in Proc. IEEE PES-ICC Fall Meeting, Scottsdale, AZ, USA, Nov. 11, 2009, pp. $1-11$.

[22] P. E. P. Barringer, "Predict failures: Crow-AMSAA 101 and Weibull 101," in Proc. Int. Mech. Eng. Conf., Kuwait, 2004, pp. 114.

[23] CIGRE Working Group A3.06, "Final report of the 2004-2007 inter- national enquiry on reliability of high voltage equipment," 2012, Part 1-Summary and General Matters, pp. 8-9.
[24] D. R.COX, "Regressionmodels and life-tables," J. Roy. Stat. Soc. Ser. B (Method.), vol. 34, no. 2, pp. 187-220, 1972.

[25] S. Sachan, C. Zhou, G. Bevan, and B. Alkali, "Failure prediction of power cables using failure history and operational conditions," in 2015 IEEE 11th International Conference on the Properties and Applications of Dielectric Materials (ICPADM), 2015, pp. 380383.

[26] Miner, M.: 'Cumulative damage in fatigue', J. Appl. Mech., 1945, 67, pp. A159-A164.

[27] K. Hermann, "Chapter 3: Technology," in Gas-Insulated Transmission Lines (GIL), JohnWiley \& Sons, Ltd., 2012, pp. 39224.

[28] A. Nami, J. Liang, F. Dijkhuizen, and G. D. Demetriades, "Modular Multilevel Converters for HVDC Applications: Review on Converter Cells and Functionalities," IEEE Trans. Power Electron., vol. 30, no. 1, pp. 18-36, Jan. 2015.

[29] F. Grilli, E. Pardo, A. Stenvall, D. N. Nguyen, Weijia Yuan, and F. Gomory, "Computation of Losses in HTS Under the Action of Varying Magnetic Fields and Currents," IEEE Trans. Appl. Supercond., vol. 24, no. 1, pp. 78-110, Feb. 2014.

[30] N. Bykovsky, "HTS high current cable for fusion application," ÉCOLE POLYTECHNIQUE FÉDÉRALE DE LAUSANNE, 2017.

[31] Nexans, "6-36kV Medium Voltage Underground Power Cables," 2009.

[32] B. S. I. S. Publication, BSI Standards Publication Electric cables - Calculation of the current rating Part 3-2 : Sections on operating conditions - Economic optimization. .

[33] M. A. Elsherif, P. C. Taylor, and D. P. Hampshire, "Power loss evaluation of hvdc and dc hts transmission solutions for round 3 offshore wind farms in the united kingdom," no. March, pp. 11-14, 2011. 